\title{
Resource subdivision and the advantage of genotypic diversity in Drosophila
}

\author{
MAURO SANTOS \\ Departament de Genètica i de Microbiologia, Universitat Autònoma de Barcelona, 08193 Bellaterra (Barcelona), \\ Spain
}

\begin{abstract}
It is noted that maintenance of genetic heterogeneity in natural populations of Drosophila, through the effect that variation in genotypic diversity across breeding sites may have on their productivity, depends not only on the effective number of parents contributing gametes to a site, as previously shown by other authors, but also on the number of loci underlying the variation in fitness. Using Monte Carlo simulation, it is found that as the number of loci increases, the effect of resource subdivision on the establishment of an initially rare allele introduced into the population becomes virtually indistinguishable from the pure drift case. It seems unlikely that this mechanism can explain the maintenance of a significant proportion of genetic variation in natural populations of Drosophila, although it may still be important in preserving linked gene complexes such as inversions.
\end{abstract}

Keywords: Drosophila, genetic heterogeneity, genetic variation, microgeographical structure, resource subdivision.

\section{Introduction}

In patchy environments, where the number of contributing parental pairs is limited within the patch size, environmental heterogeneity may arise simply because (i) genetic differences across patches exist from the sampling process, and (ii) the performance of an individual is often affected by its competing neighbours (Ayala \& Campbell, 1974; Lewontin, 1974; Maynard Smith, 1989). Even though competition is a complex phenomenon whose outcome will depend on the parameters that determine the intra- and intergenotype competitive interactions (Mather \& Caligari, 1981, 1983), experimental evidence suggests that genotypic mixtures may outyield single genotype populations (Kearsey, 1965; Caligari, 1980; Pérez-Tomé \& Toro, 1982; Ellstrand \& Antonovics, 1985; Martin et al., 1988; Kelley, 1989a; López-Suárez et al., 1993). The empirical results are not, however, always compatible with the idea that there are complementary interactions among genotypes, and in some cases no relationship has been detected between genetic heterogeneity and total production (Fowler \& Partridge, 1986; Kelley, 1989b; Bell, 1991; Burt and Bell, 1992; Garcia \& Toro, 1992). Models of competition among interbreeding genotypes show that competitive interactions can maintain genetic polymorphism (Schutz \& Usanis, 1969; Cockerham et al., 1972; Antonovics, 1978), and it would be most interesting to know if there is indeed a positive correlation between fitness and genetically variable progeny in natural populations.

Flies of the genus Drosophila are primarily consumers of the microorganisms associated with patchy and ephemeral rotting plant materials that usually support one or a few generations of flies coming from a limited number of parents (Heed, 1968; Jaenike \& Selander, 1979; Shorrocks, 1982; Lacy, 1983; Hoffmann et al., 1984; Santos et al., 1989). The general view that emerges from this resource subdivision is that of a few sibships growing together in the same habitat patch, so there will be an appreciable chance $\left(F_{\mathrm{ST}}\right)$ that two genes in the same patch will be identical by descent, relative to the whole, presumably panmictic, population. Based on the frequency-dependent selection model of Cockerham et al. (1972) and Templeton (1979), Hoffmann \& Nielsen (1985) proposed that differences in genotype fitnesses arising from the effects that genetic heterogeneity within breeding sites may have on the number of progeny emerging from each site, makes it likely that genetic polymorphisms can be maintained in natural populations. In essence, they are 
considering a patchy and physically uniform environment where genetic diversity is being maintained through interactions among genotypes, with heterogeneous groups having a higher fitness than homogeneous ones. Within-patch genetic variation for fitness in their basic model is, however, based on single gene (additive) effects. I feel that it may be more realistic to consider that many loci can be acting independently (i.e. additively) to determine the fitness of a patch. Under these circumstances, their conclusion critically depends on the number of loci involved, and maintenance of allelic diversity through interactions among competing genotypes seems unlikely with many loci. This is simply because genotypic diversity at one locus is not correlated with that at other independently segregating loci, and the level of genetic heterogeneity within breeding sites would tend to be the same as the number of loci increases.

In what follows, I first outline the Hoffmann \& Nielsen (1985) model and summarize the literature on electrophoretic data for Drosophila collected from individual breeding sites. This allows us to obtain a crude estimate of the number of flies contributing progeny to a single patch. Using Monte Carlo simulations (Jacquard, 1974), I then follow the establishment of an initially rare allele when fitness differences across breeding sites depend on various numbers of loci.

\section{The model}

Hoffmann \& Nielsen consider a random mating population subdivided into a number of ephemeral breeding sites. Within a site, the relative fitnesses of genotypes are the same, but the number of offspring produced from any one site is proportional to the variance of the genotypic values among the offspring at the site. The genetic outcome of this selection depends on the matrix of brood comparisons in Table 1 (in analogy with the competitive comparisons of Cockerham et al., 1972):

$$
\begin{gathered}
{\left[\begin{array}{ccc}
0 & W_{22}-\frac{\left(W_{13}+W_{14}\right)}{2} & W_{24}-W_{06} \\
W_{12}-W_{21} & 0 & W_{15}-W_{06} \\
W_{04}-W_{21} & W_{05}-\frac{\left(W_{13}+W_{14}\right)}{2} & 0
\end{array}\right]} \\
=\left[\begin{array}{ccc}
0 & d_{21} & d_{20} \\
d_{12} & 0 & d_{10} \\
d_{02} & d_{01} & 0
\end{array}\right] .
\end{gathered}
$$

For one locus with additive gene effects, we have the matrix:

$\left[\begin{array}{ccc}0 & 0 & \frac{1}{2} \\ \frac{1}{4} & 0 & \frac{1}{4} \\ \frac{1}{2} & 0 & 0\end{array}\right]$.

This matrix satisfies condition 1 of Cockerham et al. (1972) for a protected polymorphism: $d_{10}>0 ; d_{12}>0$. The value for $\Delta p$ in this case is

$\Delta p=\frac{\frac{1}{4} p q\left(q^{2}-p^{2}\right)}{K+p q}$,

Table 1 Fitness of offspring $\left(W_{i j}\right)$ when genotype $i$ is in brood type $j$ and gene effects are additive

\begin{tabular}{lcccc}
\hline & & \multicolumn{3}{c}{ Fitness of offspring in brood } \\
\cline { 3 - 5 } Mating & Frequency & $A A$ & $A a$ & $a a$ \\
\hline$A A \times A A$ & $\mathrm{p}^{4}$ & $W_{21}=K$ & & \\
$A A \times A a$ & $4 \mathrm{p}^{3} \mathrm{q}$ & $W_{22}=K+0.25$ & $W_{12}=K+0.25$ \\
$A A \times a a$ & $2 \mathrm{p}^{2} \mathrm{q}^{2}$ & & $W_{13}=K$ & \\
$A a \times A a$ & $4 \mathrm{p}^{2} \mathrm{q}^{2}$ & $W_{24}=K+0.5$ & $W_{14}=K+0.5$ & $W_{04}=K+0.5$ \\
$A a \times a a$ & $4 \mathrm{pq}^{3}$ & & $W_{15}=K+0.25$ & $W_{05}=K+0.25$ \\
$a a \times a a$ & $\mathrm{q}^{4}$ & & & $W_{06}=K$ \\
\hline
\end{tabular}

Number of offspring produced from any one brood (breeding site) is proportional to the constant $K$ plus the variance of the genotypic values among the offspring. 
which gives a stable equilibrium at $p=0.5$. For the dominance case (genotypic value of $A a=A A=2$ ), the matrix of brood comparisons:

$$
\left[\begin{array}{ccc}
0 & -\frac{3}{8} & \frac{3}{4} \\
0 & 0 & 1 \\
\frac{3}{4} & \frac{5}{8} & 0
\end{array}\right]
$$

also leads to a protected polymorphism under condition 3 of Cockerham et al. (1972): $d_{10}>0 ; d_{12}=0$, $d_{02}>2 d_{21}$. A stable equilibrium is attained at $p=0.314$.

A considerable change in gene frequency towards the equilibrium value in the additive model is evident in Hoffmann \& Nielsen simulations when the establishment of an initially rare allele,
$p_{0}(A)=0.025$, is followed and five or fewer mating pairs contribute progeny to a breeding site.

\section{Genetic microdifferentiation in Drosophila}

Genetic variation at the level of the between-breeding sites component can be estimated using Wright's (1951) measure of genetic differentiation, $F_{\mathrm{ST}}$. Table 2 presents some estimates of this parameter calculated for different Drosophila species. The list is not intended to be an exhaustive survey but should be representative of recent work. Computations of $F_{\mathrm{ST}}$ in Drosophila buzzatii were performed using the methods of Weir \& Cockerham (1984, refs. 1, 3, 4), and Nei \& Chesser (1983, ref. 2). The use of either method provides almost identical large sample estimates of this parameter (Chakraborty \& DankerHopfe, 1991). For the mycophagous Drosophila, $F_{\mathrm{ST}}$

Table 2 Estimates of the standardised variance $\left(F_{\text {ST }}\right)$ among breeding sites from several species of Drosophila based on allozyme variation

\begin{tabular}{|c|c|c|c|}
\hline Species and population & Breeding sites & Loci & $F_{S T}$ \\
\hline \multicolumn{4}{|l|}{ Drosophila buzzatii } \\
\hline Trinkey (Australia) ${ }^{1}$ & Opuntia cladodes & 6 & 0.059 \\
\hline Trinkey (Australia) ${ }^{1}$ & Opuntia cladodes & 6 & 0.025 \\
\hline $\mathrm{O}^{\prime}$ Hara (Australia) ${ }^{1}$ & Opuntia cladodes & 6 & 0.002 \\
\hline Grandchester (Australia) ${ }^{1}$ & Opuntia cladodes & 6 & 0.038 \\
\hline Grandchester Hill (Australia) ${ }^{1}$ & Opuntia cladodes & 6 & 0.056 \\
\hline Borallon (Australia) ${ }^{1}$ & Opuntia cladodes & 6 & 0.048 \\
\hline Hemmant (Australia) ${ }^{1}$ & Opuntia cladodes & 6 & 0.037 \\
\hline Carboneras (Spain) ${ }^{2}$ & Opuntia cladodes & 4 & 0.012 \\
\hline Trinkey (Australia) ${ }^{3}$ & Opuntia cladodes & 6 & 0.032 \\
\hline Carboneras (Spain) ${ }^{4}$ & Opuntia fruits (prickly pears) & 4 & 0.046 \\
\hline Carboneras (Spain) ${ }^{4}$ & Opuntia fruits & 4 & 0.013 \\
\hline \multicolumn{4}{|l|}{ Drosophila falleni } \\
\hline New York and Tennessee ${ }^{5}$ & Mushrooms & 3 & 0.013 \\
\hline \multicolumn{4}{|l|}{ Drosophila melanogaster } \\
\hline Wandin North (Australia) & Apples and peaches & 3 & 0.038 \\
\hline Carboneras (Spain) ${ }^{7}$ & Opuntia fruits & 3 & 0.017 \\
\hline \multicolumn{4}{|l|}{ Drosophila ordinaria } \\
\hline New York and Tennessee ${ }^{5}$ & Mushrooms & 2 & 0.019 \\
\hline \multicolumn{4}{|l|}{ Drosophila putrida } \\
\hline New York and Tennessee ${ }^{5}$ & Mushrooms & 3 & 0.014 \\
\hline \multicolumn{4}{|l|}{ Drosophila testacea } \\
\hline New York and Tennessee ${ }^{5}$ & Mushrooms & 3 & 0.011 \\
\hline \multicolumn{4}{|l|}{ Drosophila tripunctata } \\
\hline New York and Tennessee ${ }^{5}$ & Mushrooms & 4 & 0.028 \\
\hline
\end{tabular}

${ }^{1}$ Thomas \& Barker (1990); ${ }^{2}$ Quezada-Díaz (1993); ${ }^{3}$ Prout \& Barker (1993);

${ }^{4}$ Quezada-Díaz et al. (1995); ${ }^{5}$ Lacy (1983); ${ }^{6}$ Hoffmann et al. (1984); ${ }^{7}$ M. Santos

$\& \mathrm{~K}$. Th. Eisses (unpublished data). 
estimates are the average of the values for each locus and are defined as the divergence observed between populations of flies collected from various species of mushrooms, within small study sites, within years and within months (Lacy, 1983). These values are to be compared with those for Drosophila buzzatii because they make reference to the genetic differentiation among Opuntia substrates collected at the same time. For Drosophila melanogaster, $F_{\mathrm{ST}}$ was calculated as the average standardized variance across breeding sites and loci (ref. 6 in Table 2), or following Weir \& Cockerham (1984, ref. 7).

We can think of Drosophila population structure as consisting in an array of local breeding populations with high extinction and recolonization rates, where the fraction of genetic variance owing to the sampling effect of colonization among the newly founded populations is

$F_{\mathrm{ST}}(0)=\frac{1}{2 N_{0}}$,

$N_{0}$ being the effective number of locally breeding adults (Wade \& McCauley, 1988). In the model we are considering (Table 1), the fraction of these populations that survive for a generation, grow to size $N_{1}$, breed and receive a fraction $m$ of migrants from other sites is equal to 0 , which amounts to saying that breeding sites allow only one generation of flies before drying out and/or that newly emerging adults tend to disperse rather than to remain in their natal patch. This may not be true in some cases (see Thomas \& Barker, 1990), and the estimate of the effective size of locally breeding adults $\left(N_{\mathrm{e}}\right)$ from the $F_{\text {ST }}$ values would be approximately the harmonic mean size over generations (Prout \& Barker, 1993). The outcome in such cases will depend on the details of the breeding structure, but the qualitative conclusions would be the same as far as higher fitnesses are associated with those sites where both alleles are segregating at intermediate frequencies.

Using the $F_{\mathrm{ST}}$ values in Table 2, crude estimates of $N_{\mathrm{e}}$ under the assumptions of selectively neutral loci and only one round of genetic drift suggest that fewer than 20 individuals usually contribute gametes to each breeding site (the estimates range between eight and 250, with an average of 17). On empirical grounds it seems, therefore, that Hoffmann \& Nielsen's model is a plausible possibility in Drosophila natural populations, but the effect may not be very strong in most cases.

\section{Simulations}

As in Hoffmann \& Nielsen, I followed the establishment of an initially rare allele introduced at a frequency $p_{0}(A)=0.025$. From the empirical information available, five mating pairs taken at random from the whole population and contributing progeny to each breeding site were used in the simulations as

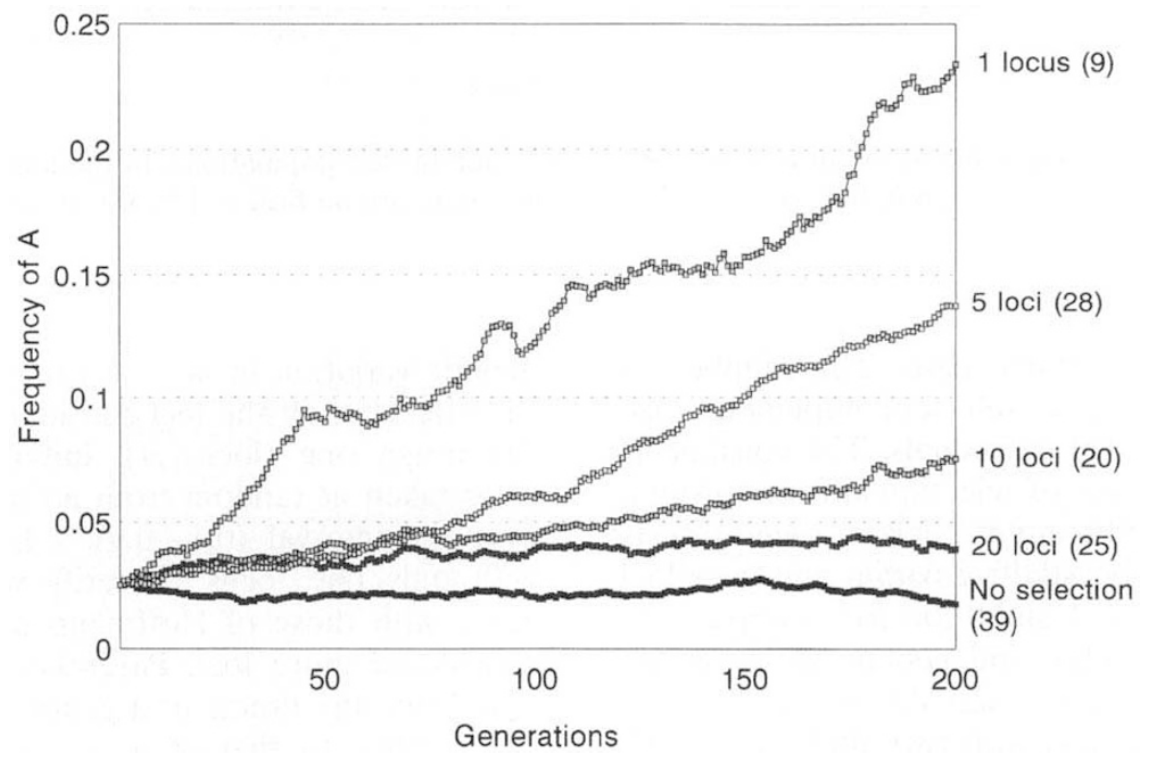

Fig. 1 Computer simulations of the establishment of an initially rare allele $\left(p_{0}(A)=0.025\right)$ in a random mating population subdivided into 100 breeding sites and five mating pairs contributing progeny to each site. Variation in fitness across breeding sites results from the segregation of $1,5,10$ and 20 autosomal loci with two alleles each. Lines are the averages over all independent runs (numbers in parentheses). 


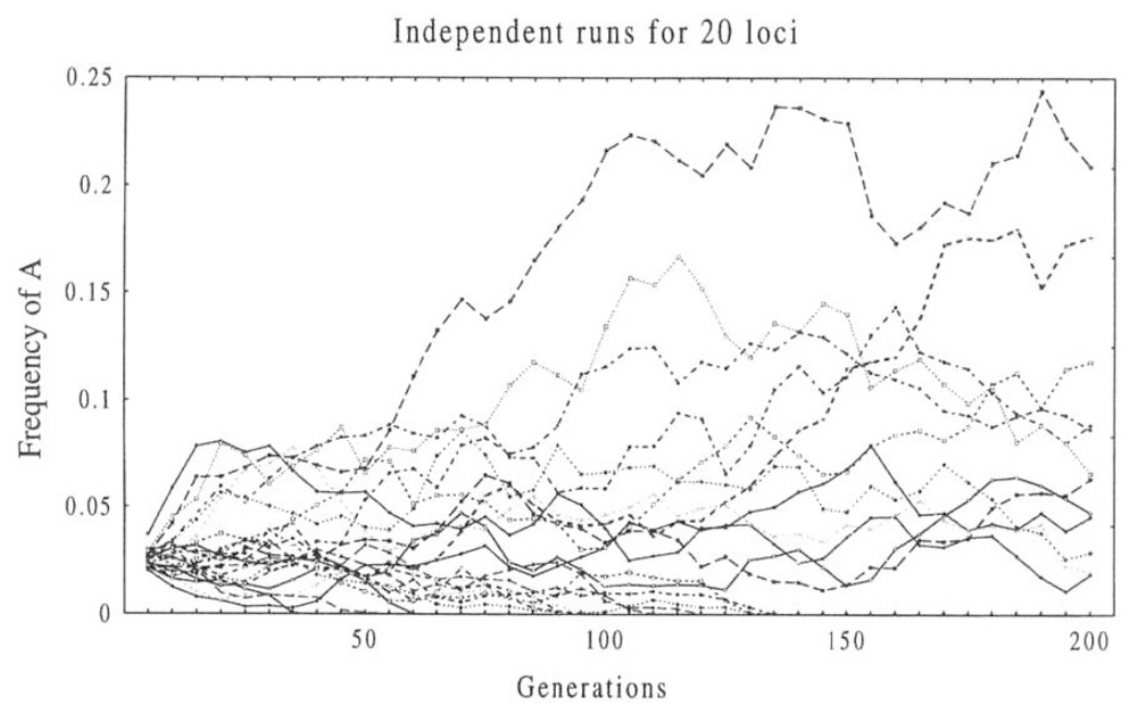

Independent runs with no selection

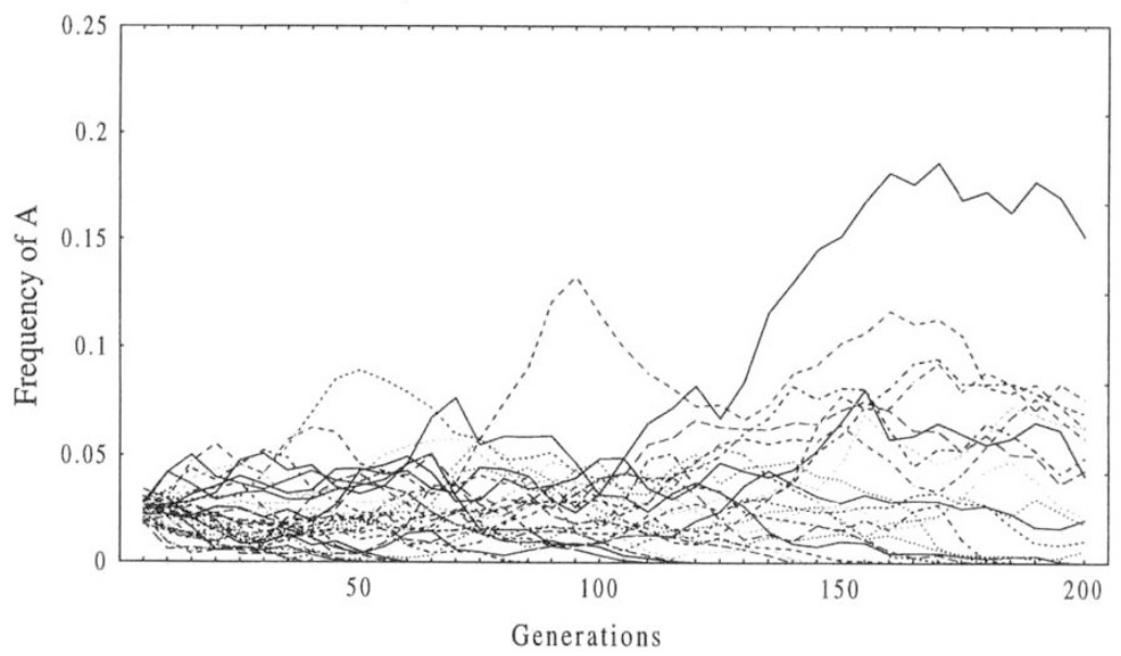

Fig. 2 Simulations of the establishment of an initially rare allele in subdivided populations. In the upper graph 20 autosomal loci contribute to variation in fitness. In the lower graph there are no fitness differences across patches.

a believable and favourable case. The number of breeding sites was set to 100 , and population size was maintained at 1000 individuals. The constant $K$ determines the intensity of selection and was given a value of 5 , as in Hoffmann \& Nielsen. Gene effects were considered to be additive within and over loci (genotypic values of 2, 1 and 0 for, for example, $A A$, $A a$ and $a a$, respectively), and genetic variation for fitness across breeding sites was determined by 1,5 , 10 and 20 autosomal loci with two alleles each. All the loci are assumed to assort independently, i.e. they are unlinked. In such an additive model, linkage disequilibrium generated by chance because of the small number of founders is ignored, and genetic variation in any breeding site is the sum of the effects of all the loci considered. For all loci but the target one (locus $A$ ), initial gene frequencies were taken at random from an uniform distribution over the interval $(0.1-0.9)$. I first ran simulations with only one locus to verify whether my results agree with those of Hoffmann \& Nielsen and then considered more loci. Parenthetically, it should be noted that the fitness of a genetically heterogeneous site relative to that of a genetically homogeneous site is

$\frac{K+V_{\mathrm{a}}}{K}$, 
where $V_{a}$ is the variance of genotypic values among the offspring at the former site. A value of 5 for $K$ yields, therefore, a very high difference in fitness between a pure and a mixed culture when several loci are contributing to the variation in fitness.

The interactive matrix algebra program MATLAB ${ }^{\circledR}$ (V. 4.0 for Windows) was used for computations, and the pseudorandom number generator was seeded before each run to make the pseudorandom numbers as 'random' as possible. The model was run on a 486 (66 Mhz) PC-compatible.

The simulations (Fig. 1) show that there is a considerable effect when only one locus is involved, in agreement with the previous results obtained by Hoffmann \& Nielsen. As the number of loci increases, however, the effect of resource subdivision on the establishment of an initially rare allele introduced into the population decreases, and there is little effect when ten or more loci are acting independently to produce the variation in fitnesses across breeding substrates. Therefore, the advantage of increasing genetic variability within breeding sites clearly depends on the number of loci involved. Figure 2 shows the independent runs when 20 loci contribute to variation in fitness, and when no fitness differences exist across patches (pure drift case). Note that part of the variation between runs in the case of 20 loci is attributable to the initially different gene frequencies at all loci but locus $A$.

\section{Discussion}

Maintenance of genetic variation through environmental heterogeneity has been suggested by assuming either genotype-environment interaction (Levene, 1953; Hedrick, 1986; Gillespie \& Turelli, 1989), or complementary interactions among genotypes (Schutz \& Usanis, 1969; Cockerham et al., 1972; Antonovics, 1978). The second mechanism proposes that if a significant proportion of genetic variation is maintained by balancing selection, that selection must be frequency-dependent.

Frequency-dependent selection has been studied in many laboratory populations of Drosophila (Curtsinger, 1990 and references therein), and maintenance of genetic variation in the use of different pupation sites in population cages of Drosophila willistoni, where polymorphic populations reach larger sizes and greater biomass than monomorphic ones, can be taken as a good example (De Souza et al., 1970). We do not know, however, whether the laboratory examples are representatives of a widespread phenomenon.
In the Hoffmann \& Nielsen model there seems to be a trade-off between founder events producing variability among breeding sites, and a large number of offspring. Martin et al. (1988), working with Drosophila melanogaster, showed that productivity is not related to genotypic variability unless larval competition is strong and viability is greatly reduced. These results suggest that strong density-dependent mortality, in addition to subdivision into discrete breeding sites, is also a basic ingredient of the model. As far as I know, density-dependent mortality in nature has only been shown to occur in Drosophila falleni, Drosophila putrida (Grimaldi \& Jaenike, 1984) and Drosophila buzzatii (QuezadaDíaz et al., 1995). In the latter species, larval mortality in Opuntia fruits is very high (approximately 78 per cent), but the fraction of genetic variance owing to the sampling effect provided an estimate of 30 individuals contributing progeny to a fruit (Quezada-Díaz et al., 1995). Therefore, very little subdivision, and hence very little selection, probably takes place to overcome the pure drift case (see Hoffmann \& Nielsen, 1985).

In addition to the density effect, the genetic basis of the variance in fitness across breeding sites is also relevant. The advantage of resource subdivision decreases with the number of loci. It seems, therefore, that maintenance of genetic variation by means of resource subdivision in natural populations of Drosophila would require: (i) that the fraction of genetic variance owing to the sampling effect of colonization should be not lower than approximately 0.025 (i.e. fewer than ten mating pairs should contribute progeny to a breeding site (see Hoffmann \& Nielsen, 1985); (ii) relatively strong density-dependent mortality within breeding sites; and (iii) single gene effects strong enough to produce 'overcompensatory' effects, defined as the differential exploitation of the available resources by alternative genotypes (Tosic \& Ayala, 1980; Milosevic et al., 1990; Peng et al., 1991). In such situations, the yield of a mixed culture can be expected to be greater than that of a pure culture. It has been shown, however, that differential exploitation of an environment by competitors need not always result in overcompensation (Case et al., 1979; Nunney, 1980). Conversely, there may be a higher yield in mixtures than in pure cultures even in the absence of differential resource utilization (Nunney, 1983). Overcompensation has been invoked as an important mechanism to account for the maintenance of enzyme polymorphisms in Drosophila. Examples are the Mdh-2 locus in Drosophila pseudoobscura (Tosic \& Ayala, 1980), and the Sod locus in Drosophila 
melanogaster (Peng et al., 1991), although nonrandom associations with alleles at other closely linked loci cannot be rejected. I show here, however, that there are serious objections to the view that this form of environmental heterogeneity can account for a significant amount of genetic variation. To put it in a paradoxical way, the more empirical work is published that supports overcompensation as a form of balancing selection at individual loci, either arising as a consequence of differential exploitation of the available resources or differences in resource preference (Nunney, 1983), the nearer we will be to the pure drift situation because these individual effects would cancel out each other across breeding sites (Fig. 1). Notice that in the simulations involving various loci, condition 1 of Cockerham et al. (1972) for a protected polymorphism is satisfied for any locus taken individually and, therefore, a stable equilibrium should in theory be attainable at $p=0.5$ for both alleles. Genotypic diversity at one locus is not, however, correlated with that at another locus, and the level of genetic heterogeneity within breeding sites tends to be the same as the number of loci increases.

In summary, genotype diversity may have an effect on juvenile survival in Drosophila, but I doubt that it can count as a general mechanism to maintain genetic variation. Nevertheless, the mechanism may still be important in preserving linked gene complexes such as inversions. There is evidence that chromosomally polymorphic populations outyield monomorphic ones (Dobzhansky, 1970), and that different inversion types may show frequencydependent interactions (Levene et al., 1954; Kojima \& Tobari, 1969; Anderson et al., 1986). The inversions involve a sizable part of the genome, and recombination in a structurally homozygous individual would tend to destroy interacting polymorphic genes. This may cause a recombination load which is frequency dependent (Wasserman, 1968, 1972; Charlesworth \& Charlesworth, 1975), and the population may remain chromosomally polymorphic. A higher productivity of chromosomally heterogeneous breeding sites may superimpose, and the point of equilibrium would be a function of the joint effect from the two mechanisms.

\section{Acknowledgements}

J. E. Quezada-Díaz's good humour during the field trips to sample Drosophila buzzatii at Carboneras (Spain) and the many gels run in the laboratory is very much appreciated. The manuscript was greatly improved from suggestions provided by two anony- mous reviewers. The final version of the manuscript was written while the author was on sabbatical leave in the Department of Ecology and Evolutionary Biology, University of California, Irvine. I am grateful to my host, Larry D. Mueller, for providing a stimulating intellectual environment, and to Daniel J. Borash for his continuous help. Funds have been provided by the Dirección General de Investiación Científica y Técnica (DGICYT), Spain. This work was partly supported by grant PB93-0843 from the DGICYT to A. Fontdevila.

\section{References}

ANDERSON, W. W., ARNOLD, J., SAMMONS, S. A. AND YARDLEY, D. G. 1986. Frequency-dependent viabilities of Drosophila pseudoobscura karyotypes. Heredity, 56, 7-17.

ANTONOVICS, J. 1978. The population genetics of mixtures. In Wilson, J. R. (ed.) Plant Relations in Pastures, pp. 233-252. CSIRO, Melbourne, Australia.

AYALA, F. J. AND CAMPBELL, C. A. 1974. Frequency-dependent selection. Ann. Rev. Ecol. Syst., 5, 115-138.

BELL, G. 1991. The ecology and genetics of fitness in Chlamydomonas. IV. The properties of mixtures of genotypes of the same species. Evolution, 45, 1036-1046.

BURT, A. AND BELL, G. 1992. Tests of sib diversification theories of outcrossing in Impatiens capensis: effects of inbreeding and neighbor relatedness on production and infestation. J. Evol. Biol., 5, 575-588.

CALIGARI, P. D. S. 1980. Competitive interactions in Drosophila melanogaster. I. Monocultures. Heredity, 45, 219-231.

CASE, T. J., GILPIN, M. E., AND DIAMOND, J. M. 1979. Overexploitation, interference competition, and excess density compensation in insular faunas. Am. Nat., 113, 843-854.

CHAKRABORTY, R. AND DANKER-HOPFE, H. 1991. Analysis of population structure: a comparative study of different estimators of Wright's fixation indices. In Rao, C. R. and Chakraborty, R. (eds) Handbook of Statistics, vol. 8, pp. 203-254. Elsevier Science Publishers, Amsterdam.

CHARLESWORTH, B. AND CHARLESWORTH, D. 1975. An experiment on recombination load in Drosophila melanogaster. Genet. Res., 25, 267-274.

COCKERHAM, C. C., BURROWS, P. M., YOUNG, S. S. AND PROUT, T. 1972. Frequency-dependent selection in randomly mating populations. Am. Nat., 106, 493-515.

CURTSINGER, J. w. 1990. Frequency-dependent selection in Drosophila: estimation of net fitness in pseudohaploid populations. Evolution, 44, 857- 869.

DE SOUZA, H. M. L., DA CUNHA, A. B. AND DOS SANTOS, E. P. 1970. Adaptive polymorphism of behavior evolved in laboratory populations of Drosophila willistoni. Am. Nat., 104, 175-189.

DOBZHANSKY, TH. 1970. Genetics of the Evolutionary 
Process. Columbia University Press, New York.

ELLSTRAND, N. AND ANTONOVICS, J. 1985. Experimental studies of the evolutionary significance of sexual reproduction. II. A test of the density-dependent selection hypothesis. Evolution, 39, 657-666.

FOWLER, K. AND PARTRIDGE, L. 1986. Variation in male fertility explains an apparent effect of genotypic diversity on success in larval competition in Drosophila melanogaster. Heredity, 57, 31-36.

GARCIA, C. AND TORO, M. A. 1992. Sib competition in Tribolium: a test of the elbow-room model. Heredity, $\mathbf{6 8}$, 529-536.

GILLESPIE, J. H. AND TURELLI, M. 1989. Genotype-environment interactions and maintenance of polygenic variation. Genetics, 121, 129-138.

GRIMALDI, D. AND JAENIKE, J. 1984. Competition in natural populations of mycophagous Drosophila. Ecology, 65, 1113-1120.

HEDRICK, P. W. 1986. Genetic polymorphism in heterogeneous environments: a decade later. Ann. Rev. Ecol. Syst., 17, 535-566.

HEED, w. B. 1968. Ecology of the Hawaiian Drosophilidae. University of Texas Publications, 6818, 387-419.

HOFFMANN, A. A. AND NIELSEN, K. M. 1985. The effect of resource subdivision on genetic variation in Drosophila. Am. Nat., 125, 421-430.

HOFFMANN, A. A., NIELSEN, K. M. AND PARSONS, P. A. 1984. Spatial variation of biochemical and ecological phenotypes in Drosophila: electrophoretic and quantitative variation. Devl. Genet., 4, 439-450.

JACQuARD, A. 1974. The Genetic Structure of Populations. Biomathematics, vol. 5. Springer, Berlin.

JAENIKE, J. AND SELANDER, R. K. 1979. Ecological generalism in Drosophila falleni: genetic evidence. Evolution, 33, 741-748.

KEARSEY, M. J. 1965. The interaction of food supply and competition in two lines of Drosophila melanogaster. Heredity, 20, 169-181.

KELLEY, S. E. 1989a. Experimental studies of the evolutionary significance of sexual reproduction. V. A field test of the sib-competition lottery hypothesis. Evolution, 43, 1054-1065.

KELLEY, S. E. $1989 \mathrm{~b}$. Experimental studies of the evolutionary significance of sexual reproduction. VI. A greenhouse test of the sib-competition hypothesis. Evolution, 43, 1066-1074.

KOJIMA, K. AND TOBARI, Y. N. 1969. Selective modes associated with karyotypes in Drosophila ananassae. II. Heterosis and frequency-dependent selection. Genetics, 63, 639-651.

LACY, R. C. 1983. Structure of genetic variation within and between populations of mycophagous Drosophila. Genetics, 104, 81-94.

LEVENE, H. 1953. Genetic equilibrium when more than one ecological niche is available. Am. Nat., 87, 331-333.

LEVENE, H., PAVLOVSKY, O. AND DOBZHANSKY, TH. 1954. Interaction of the adaptive values in polymorphic experimental populations of Drosophila pseudoobscura. Evolution, 8, 335-349.
LEWONTIN, R. C. 1974. The Genetic Basis of Evolutionary Change. Columbia University Press, New York.

LÓPEZ-SUÁREZ, C., TORO, M. A. AND GARCIA, C. 1993. Genetic heterogeneity increases viability in competing groups of Drosophila hydei. Evolution, 47, 977-981.

MARTIN, M. J., PÉREZ-TOMÉ, J. M. AND TORO, M. A. 1988. Competition and genotypic variability in Drosophila melanogaster. Heredity, 60, 119-123.

MATHER, K. AND CALIGARI, P. D. s. 1981. Competitive interactions in Drosophila melanogaster. II. Measurement of competition. Heredity, 46, 239-254.

Mather, K. AND CAligari, P. D. S. 1983. Pressure and response in competitive interactions. Heredity, $\mathbf{5 1}$ 435-454.

MATLAB ${ }^{\circledR}$ Reference Guide. 1992. The MathWorks, Massachusetts.

MAYNARD SMITH, J. 1989. Evolutionary Genetics. Oxford University Press, Oxford.

MILOSEVIC, M., MOYA, A. AND AYALA, F. I. 1990. Overcompensation as a mechanism for maintaining polymorphism: egg-to-adult viability in Drosophila. Genetica, 82, $183-187$.

NEl, M. AND CHEESER, R. K. 1983. Estimation of fixation indices and gene diversities. Ann. Hum. Genet., 47, 253-259.

NUNNEY, L. 1980. Density compensation, isocline shape and single-level competition models. J. Theor. Biol., 86, 323-349.

NUNNEY, L. 1983. Sex differences in larval competition in Drosophila melanogaster: the testing of a competition model and its relevance to frequency-dependent selection. Am. Nat., 121, 67-93.

PENG, T. X., MOYA, A. AND AYALA, F. J. 1991. Two models of balancing selection in Drosophila melanogaster: overcompensation and overdominance. Genetics, 128, 381-391.

PÉREZ-TOMÉ, J. M. AND TORO, M. A. 1982. Competition of similar and non-similar genotypes. Nature, 229, 153-154.

PROUT, T. AND BARKER, J. S. F. 1993. $F$ statistics in Drosophila buzzatii: selection, population size and inbreeding. Genetics, 134, 369-375.

Quezada-Díaz, J. E. 1993. Estructura Poblacional y Patrón de Apareamientos en la Especie Cactófila Drosophila buzzatii. Ph.D. Thesis, Universitat Autònoma de Barcelona, Spain.

SANTOS, M., RUIZ, A. AND FONTDEVILA, A. 1989. The evolutionary history of Drosophila buzzatii. XIII. Random differentiation as a partial explanation of chromosomal variation in a structured natural population. Am. Nat., 133, 183-197.

SHORROCKs, B. 1982. The breeding sites of temperate woodland Drosophila. In: Ashburner, M., Carson, H. L. and Thompson, J. N., Jr (eds) The Genetics and Biology of Drosophila, vol. 3b, pp. 385-428. Academic Press, London.

SCHUTZ, w. M. AND USANIS, s. A. 1969. Intergenotypic competition in plant populations. II. Maintenance of allelic polymorphisms with frequency-dependent selec- 
tion and mixed selfing and random mating. Genetics, 61, 875-891.

TEMPLETON, A. R. 1979. A frequency dependent model of brood selection. Am. Nat., 114, 515-524.

THOMAS, R. H. AND BARKER, J. S. F. 1990. Breeding structure of natural populations of Drosophila buzzatii: effects of the distribution of larval substrates. Heredity, 64, 355-365.

TOSIC, M. AND AYALA, F. J. 1980. 'Overcompensation' at an enzyme locus in Drosophila pseudoobscura. Genet. Res., 36, 57-67.

WADE, M. J. AND McCAuley, D. E. 1988. Extinction and recolonization: their effects on the genetic differentiation of local populations. Evolution, 42, 995-1005.

WASSERMAN, M. 1968. Recombination-induced chromosomal heterosis. Genetics, 58, 125-139.

WASSERman, M. 1972. Factors influencing fitness in chromosomal strains in Drosophila subobscura. Genetics, 72, 691-708.

WEIR, B. S. AND COCKERHAM, C. C. 1984 . Estimating $F$-statistics for the analysis of population structure. Evolution, 38, 1358-1370.

WRIGHT, s. 1951. The genetical structure of populations. Ann. Eugen., 15, 323-354. 